\title{
(6) OPEN ACCESS \\ The effects of absence of stereopsis on performance of a simulated surgical task in two-dimensional and three-dimensional viewing conditions
}

\author{
Edward Bloch, ${ }^{1,2}$ Nabil Uddin, ${ }^{1}$ Laura Gannon, ${ }^{1}$ Khadija Rantell, ${ }^{3}$ Saurabh Jain ${ }^{1,2}$
}

\begin{abstract}
${ }^{1}$ Department of
Ophthalmology, Royal Free London NHS Foundation Trust, London, UK

${ }^{2}$ University College London Medical School, London, UK ${ }^{3}$ Institute of Neurology, University College London, London, UK
\end{abstract}

\section{Correspondence to} Saurabh Jain, Department of Ophthalmology, Royal Free Hospital, Pond Street, London NW3 2QG, UK; saurabh.jain@nhs.net

EB and NU contributed equally and should be considered cofirst authors.

Received 22 October 2013 Revised 20 July 2014 Accepted 8 August 2014 Published Online First 3 September 2014

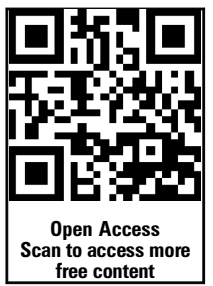

CrossMark

To cite: Bloch $\mathrm{E}$, Uddin $\mathrm{N}$, Gannon L, et al. Br J Ophthalmol 2015;99:240245

\section{ABSTRACT \\ Background Stereopsis is believed to be advantageous for surgical tasks that require precise hand-eye coordination. We investigated the effects of short-term and long-term absence of stereopsis on motor task performance in three-dimensional (3D) and two- dimensional (2D) viewing conditions.}

Methods 30 participants with normal stereopsis and 15 participants with absent stereopsis performed a simulated surgical task both in free space under direct vision (3D) and via a monitor (2D), with both eyes open and one eye covered in each condition.

Results The stereo-normal group scored higher, on average, than the stereo-absent group with both eyes open under direct vision $(p<0.001)$. Both groups performed comparably in monocular and binocular monitor viewing conditions ( $p=0.579$ ).

Conclusions High-grade stereopsis confers an advantage when performing a fine motor task under direct vision. However, stereopsis does not appear advantageous to task performance under $2 \mathrm{D}$ viewing conditions, such as in video-assisted surgery.

\section{INTRODUCTION}

Stereopsis was first described in 1838 by Charles Wheatstone, the inventor of the stereoscope. $\mathrm{He}$ established that the human brain computes the disparities between images presented to each retina, giving rise to an inherent impression of solidity and relative depth. ${ }^{1}$ It has been debated whether stereopsis is truly a functional necessity for humans; Fielder and Moseley suggest that it may well be beneficial for certain tasks involving complex visual presentations and hand-eye coordination. ${ }^{2}$

Minimally invasive surgery is used in various specialities, requiring a novel set of motor skills and adaptation to a different viewing condition. The three-dimensional (3D) operative field is magnified and displayed on a monitor, which provides a live two-dimensional (2D) video representation. This system prevents the use of stereopsis, forcing the surgeon to rely on other visual and haptic cues.

This study has been designed to demonstrate the effects of acute elimination and long-term absence of stereopsis on the performance of a fine motor task under different viewing conditions.

\section{MATERIALS AND METHODS \\ Participants}

A total of 45 participants, were recruited into the study from the University College London Medical School, the Royal Free and the Whittington hospitals. Two-thirds $(30 / 45)$ of the participants were stereo-normal, and the remainder (15/45) were stereo-absent. Inclusion criteria required all participants to be aged $18-45$ years, while those currently undergoing eye treatment and those with known motor or co-ordination problems were excluded.

Participant clinical and ophthalmic history, including the pre-existence of any conditions affecting balance or coordination, was ascertained at screening by a clinician using a questionnaire designed for this study. This included questions regarding experience that may affect dexterity (such as video games and musical instruments). No participant had had any formal minimally invasive surgical training. Participants were unaware of the other test group, and information was limited to reduce demand characteristics.

All participants underwent orthoptic assessment, including best corrected visual acuities (recorded with an ETDRS chart at $6 \mathrm{~m}$ and reduced Snellen at $33 \mathrm{~cm}$ ), ocular alignment, ocular motility, convergence and assessment of sensory and motor fusion. Stereoacuity was measured to threshold using the Frisby Near Stereotest or Wirt Fly Stereotest for detection of the coarsest stereoacuity possible in clinic ( $3600 \mathrm{~s}$ of arc) Laterality of the dominant eye was determined from visual acuities and objective assessment of convergence using a Royal Air Force rule. In the stereo-normal group, participants were required to have best corrected visual acuities of $0.200 \log$ MAR (6/9.5 Snellen equivalent) or better in both eyes, convergence of within $12 \mathrm{~cm}$, fusional amplitudes of more than $25 \mathrm{BO}$ to $10 \mathrm{BI}$ for near, and $12 \mathrm{BO}$ to $4 \mathrm{BI}$ for distance, and stereopsis of at least $55^{\prime \prime}$ arc. $^{3}$ In the stereo-absent group, participants were required to have a best corrected visual acuity of 0.200 logMAR (6/9.5) or better from at least one eye, the presence of suppression for near and distance (ie, no demonstrable sensory fusion using worth lights) and an absence of stereopsis (table 1).

\section{Task}

The participants performed a 'pea-on-a-peg' motor skills task which involved placing small plastic balls on columns of various heights using laparoscopic graspers (figure 1). Performance was quantified according to the number of balls placed in the allotted time. The order of ball placement was prespecified to prevent strategy.

The task was performed under direct vision and via a monitor, part of a laparoscopic 'box trainer' simulation machine (3Dmed Minimally Invasive Training System (figures 2 and 3)). Each condition was repeated with both eyes open and one eye 
Table 1 Characteristics of the stereo-absent participant group

\begin{tabular}{|c|c|c|c|c|c|c|c|c|c|c|}
\hline \multirow[b]{2}{*}{ Part. } & \multirow[b]{2}{*}{ Age } & \multirow[b]{2}{*}{$\begin{array}{l}\text { Deviation (all constant } \\
\text { manifest strabismus) }\end{array}$} & \multirow[b]{2}{*}{$\begin{array}{l}\text { Near } \\
\text { angle }\end{array}$} & \multirow[b]{2}{*}{$\begin{array}{l}\text { Distance } \\
\text { angle }\end{array}$} & \multicolumn{3}{|c|}{$\begin{array}{l}\text { Best corrected visual acuity } \\
\text { (LogMAR) }\end{array}$} & \multirow[b]{2}{*}{$\begin{array}{l}\text { Dominant } \\
\text { eye }\end{array}$} & \multirow[b]{2}{*}{ Suppression } & \multirow[b]{2}{*}{ Additional information } \\
\hline & & & & & $\begin{array}{l}\text { Both eyes } \\
\text { open }\end{array}$ & $\begin{array}{l}\text { Right } \\
\text { eye }\end{array}$ & $\begin{array}{l}\text { Left } \\
\text { eye }\end{array}$ & & & \\
\hline 1 & 27 & $\begin{array}{l}\text { Right to alternating } \\
\text { exotropia }\end{array}$ & $\mathrm{n} / \mathrm{a}$ & $\mathrm{n} / \mathrm{a}$ & 0.200 & 0.220 & 0.340 & Left* $^{*}$ & Yes & Myopia, X pattern \\
\hline 2 & 36 & Exotropia & $10 \Delta \mathrm{BI}$ & $10 \Delta \mathrm{BI}$ & -0.040 & -0.040 & 0.040 & Right & Yes & \\
\hline 3 & 34 & Residual exotropia & $4 \Delta \mathrm{BI}$ & $4 \Delta \mathrm{BI}$ & 0.200 & 0.220 & 1.600 & Right & Yes & Right eye aphakia \\
\hline 4 & 34 & Consecutive exotropia & $12 \Delta \mathrm{BI}$ & $14 \Delta \mathrm{BI}$ & 0.000 & 0.120 & 0.020 & Left & Yes & \\
\hline 5 & 35 & Sensory exotropia & $8 \Delta \mathrm{BI}$ & $8 \Delta \mathrm{BI}$ & 0.000 & 1.300 & 0.000 & Left & Yes & \\
\hline 6 & 26 & Exotropia & $45 \Delta \mathrm{BI}$ & $45 \Delta \mathrm{BI}$ & 0.000 & 0.040 & 0.800 & Right & Yes & \\
\hline 7 & 42 & Exotropia & $40 \Delta \mathrm{BI}$ & $38 \Delta \mathrm{BI}$ & -0.200 & -0.100 & 1.040 & Right & Yes & \\
\hline 8 & 37 & Alternating L/R & $25 \Delta \mathrm{L} / \mathrm{R}$ & $20 \Delta \mathrm{L} / \mathrm{R}$ & 0.000 & 0.000 & 0.000 & Left & Yes & Left 4th nerve palsy \\
\hline 9 & 23 & $\begin{array}{l}\text { Left to alternating } \\
\text { exotropia }\end{array}$ & $40 \Delta \mathrm{BI}$ & $45 \Delta \mathrm{BI}$ & 0.060 & 0.100 & 0.320 & Right & Yes & $\begin{array}{l}\text { Dissociated vertical deviation, } \\
\text { no manifest latent nystagmus }\end{array}$ \\
\hline 10 & 23 & $\begin{array}{l}\text { Sensory residual } \\
\text { exotropia and } \mathrm{R} \\
\text { hypotropia }\end{array}$ & $\begin{array}{l}4 \Delta \mathrm{BI} \text { and } \\
5 \Delta \mathrm{L} / \mathrm{R}\end{array}$ & $\begin{array}{l}2 \Delta \mathrm{BI} \text { and } \\
6 \Delta \mathrm{L} / \mathrm{R}\end{array}$ & 0.000 & 1.040 & 0.000 & Left & Yes & Superior rectus underaction \\
\hline 11 & 38 & Sensory exotropia & $30 \Delta \mathrm{BI}$ & $30 \Delta \mathrm{BI}$ & 0.040 & 1.000 & 0.120 & Left & Yes & $\begin{array}{l}\text { Y pattern, bilateral inferior } \\
\text { oblique overaction }\end{array}$ \\
\hline 12 & 21 & $\begin{array}{l}\text { Exotropia and L } \\
\text { hypertropia }\end{array}$ & $\begin{array}{l}25 \Delta \mathrm{BI} \text { and } \\
2 \Delta \mathrm{L} / \mathrm{R}\end{array}$ & $\begin{array}{l}30 \Delta \mathrm{BI} \text { and } \\
2 \Delta \mathrm{L} / \mathrm{R}\end{array}$ & 0.200 & 0.200 & $\mathrm{CF}$ & Right & Yes & Y pattern, pseudophakia \\
\hline 13 & 24 & Esotropia & $14 \Delta \mathrm{BO}$ & $16 \Delta B)$ & -0.080 & -0.080 & 0.100 & Right & Yes & \\
\hline 14 & 26 & Esotropia & $10 \Delta \mathrm{BO}$ & $8 \Delta B O$ & -0.100 & 0.080 & -0.100 & Left & Yes & \\
\hline 15 & 25 & Exotropia & $14 \Delta \mathrm{BI}$ & $10 \Delta \mathrm{BI}$ & -0.100 & -0.060 & -0.060 & Right & Yes & \\
\hline
\end{tabular}

occluded. The order of the four test conditions was randomised, with three attempts of $50 \mathrm{~s}$ allowed for each. Monocular conditions were established by occluding the non-dominant eye with an opaque patch, and participants wore refractive correction where necessary. Both the box trainer and the 'pea-on-a-peg' task are validated methods for simulated laparoscopy skills training. ${ }^{4}$

A pilot study of 10 participants revealed that there is, as expected, an element of improvement in performance with practice. We expected this and have attempted to control for it by establishing an optimal familiarisation period $(5 \mathrm{~min})$ to minimise the confounding effects of initial improvement.

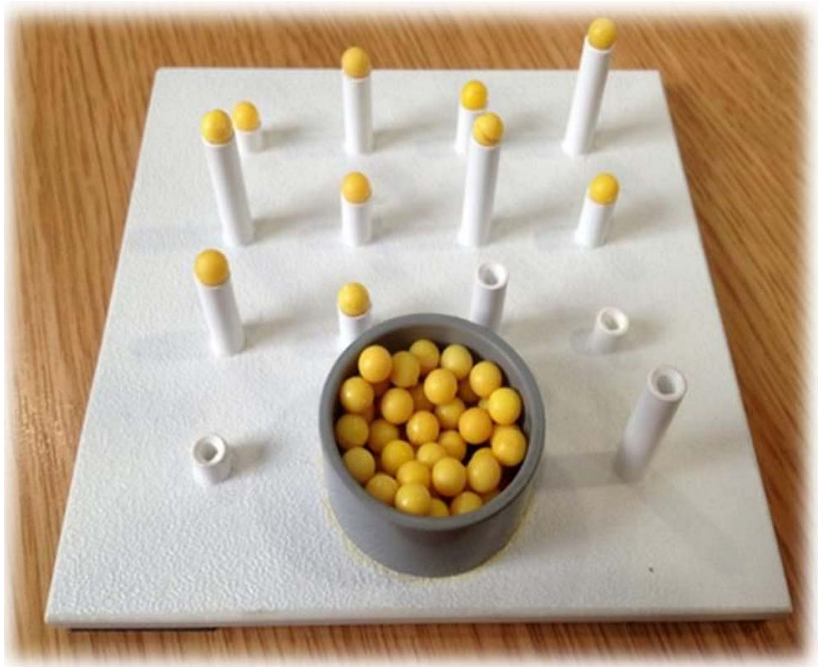

Figure 1 The 'pea-on-a-peg' task.

\section{Statistical analysis}

Numerical data were summarised using mean and SD or median and range, depending on data distribution. Categorical data were summarised using count and percentages. The relationship between the performance of fine motor task and stereopsis was assessed using a multilevel linear regression model with participants as random effect, and group as fixed effects. ${ }^{5}$ The multilevel model takes into account the correlation structure of the

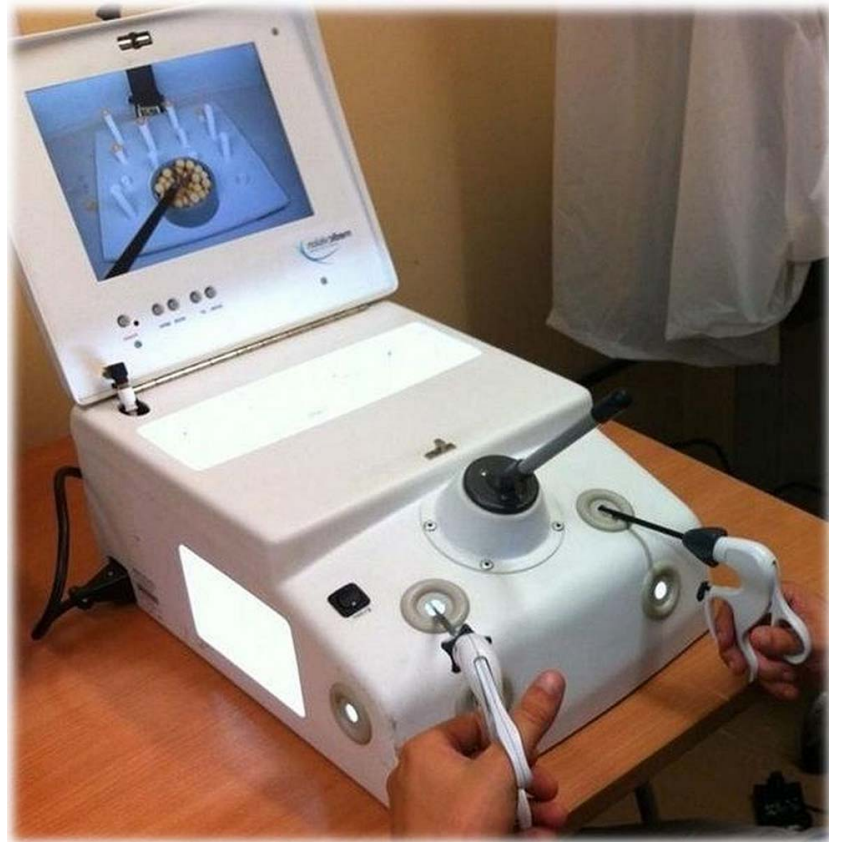

Figure 2 3D med Minimally Invasive Training System. 


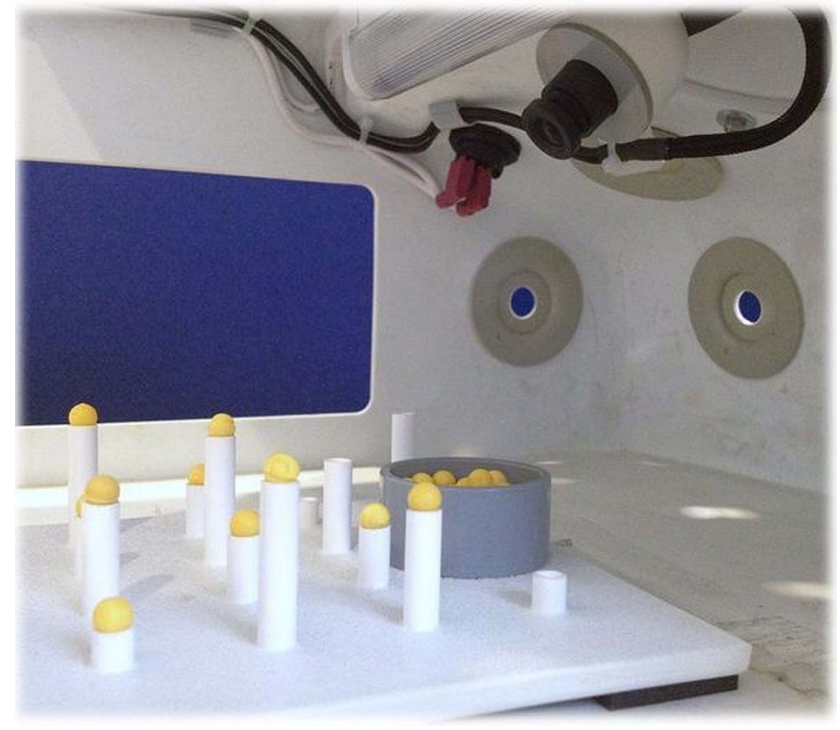

Figure 3 3D med Minimally Invasive Training System.

data, providing estimates of effects and their 95\% CI. The data were analysed using Stata V.13 (SPSS statistics).

Informed consent was obtained, and the research protocol was approved by the Camberwell St Giles Research Ethics Committee observing the tenets of the Declaration of Helsinki.

\section{RESULTS}

Thirty stereo-normal participants with a mean age of 27.0 years and a female to male ratio 1:2 were recruited into the control group. Fifteen stereo-absent participants were recruited into the study group, with a mean age of 30.1 years, and female to male ratio 7:8. All participants in this group had manifest strabismus (see table 1).

It was found that, in free space under direct (3D) viewing conditions, the stereo-normal group (average stereoacuity of $37.7^{\prime \prime}$ ) placed more balls on average $( \pm$ SEM) with both eyes open (12.1 $\pm 0.30)$ compared with one eye occluded $(9.9 \pm 0.44)$ in the allocated time of $50 \mathrm{~s}$ (table 2). The estimated difference of means was 2.22 (95\% CI 1.46 to 2.98) and $\mathrm{p}<0.001$ (table 3).

In the same condition, the stereo-absent group placed an average of $9.1 \pm 0.50$ balls with both eyes open, compared with $8.5 \pm 0.55$ balls with one eye occluded (table 4 ). The estimated difference of means was $0.622(95 \%$ CI -0.45 to 1.70$)$ and $\mathrm{p}=0.260$.

The stereo-normal group performed significantly better than the stereo-absent group under binocular direct vision with an estimated difference between group means of 3.03 (95\% CI 1.84 to 4.22 ) and $\mathrm{p}<0.001$. The performance of the stereonormal group under monocular conditions was also better compared to that of the stereo-absent group, with an estimated difference of means of 1.43 (95\% CI 0.24 to 2.62) and a $\mathrm{p}=0.018$ (figure 4).

Under monitor (2D) viewing conditions, we found no statistical difference in average number of balls placed within or between groups. Pairwise comparison within the multilevel model demonstrated that stereo-normal group performance with both and one eye open $(6.6 \pm 0.37$ and $6.3 \pm 0.32$ balls, respectively) was comparable to that of the stereo-absent group $(6.0 \pm 0.50$ and $6.3 \pm 0.44$ balls), with an estimated difference of means of 0.29 (95\% CI -0.70 to 1.28 ) and $\mathrm{p}=0.579$ (figure 5, table 3).
Table 2 Stereo-normal group results

\begin{tabular}{|c|c|c|c|c|}
\hline \multirow{3}{*}{$\begin{array}{l}\text { Stereo-normal } \\
\text { participant }\end{array}$} & \multicolumn{4}{|c|}{ Number of balls in $50 \mathrm{~s}$ (mean of 3 attempts) } \\
\hline & \multicolumn{2}{|l|}{ Free space } & \multicolumn{2}{|l|}{ Monitor } \\
\hline & Both eyes & One eye & Both eyes & One eye \\
\hline 1 & 13.33 & 11.00 & 5.67 & 6.00 \\
\hline 2 & 13.33 & 10.00 & 6.33 & 5.00 \\
\hline 3 & 11.33 & 12.00 & 8.33 & 6.00 \\
\hline 4 & 12.00 & 7.33 & 4.67 & 4.33 \\
\hline 5 & 11.33 & 5.33 & 7.00 & 6.67 \\
\hline 6 & 9.00 & 4.67 & 3.33 & 6.67 \\
\hline 7 & 9.67 & 9.33 & 7.67 & 5.33 \\
\hline 8 & 12.00 & 11.33 & 3.67 & 7.33 \\
\hline 9 & 12.67 & 13.00 & 10.00 & 8.67 \\
\hline 10 & 10.33 & 7.33 & 4.33 & 5.67 \\
\hline 11 & 13.00 & 10.33 & 8.33 & 8.33 \\
\hline 12 & 12.00 & 8.67 & 2.67 & 4.33 \\
\hline 13 & 10.00 & 8.33 & 7.00 & 7.33 \\
\hline 14 & 13.33 & 10.67 & 7.67 & 7.33 \\
\hline 15 & 10.33 & 5.67 & 7.33 & 5.00 \\
\hline 16 & 13.33 & 12.33 & 8.00 & 5.67 \\
\hline 17 & 16.00 & 14.33 & 10.33 & 8.67 \\
\hline 18 & 12.33 & 10.33 & 7.00 & 6.33 \\
\hline 19 & 15.00 & 10.67 & 5.33 & 6.33 \\
\hline 20 & 14.00 & 11.00 & 6.00 & 1.00 \\
\hline 21 & 11.00 & 10.33 & 4.33 & 4.67 \\
\hline 22 & 9.33 & 11.00 & 6.00 & 6.67 \\
\hline 23 & 12.67 & 7.00 & 9.33 & 9.33 \\
\hline 24 & 11.33 & 8.33 & 7.33 & 6.67 \\
\hline 25 & 13.33 & 10.33 & 9.00 & 8.00 \\
\hline 26 & 11.00 & 9.67 & 3.00 & 3.33 \\
\hline 27 & 14.00 & 13.67 & 7.67 & 7.00 \\
\hline 28 & 12.67 & 9.33 & 7.33 & 7.67 \\
\hline 29 & 12.00 & 10.67 & 5.00 & 8.00 \\
\hline 30 & 12.00 & 13.00 & 7.33 & 7.00 \\
\hline Mean & 12.12 & 9.90 & 6.57 & 6.34 \\
\hline SEM & 0.30 & 0.44 & 0.37 & 0.32 \\
\hline
\end{tabular}

Table 3 Multilevel model posthoc pairwise and three-way analysis

\begin{tabular}{|c|c|c|c|c|c|}
\hline Comparison & $\begin{array}{l}\text { Estimated } \\
\text { difference } \\
\text { of means }\end{array}$ & $95 \% \mathrm{Cl}$ & & SEM & $p$ Value \\
\hline $\begin{array}{l}\text { Stereo-normal free space } \\
\text { binocular vs monocular }\end{array}$ & 2.22 & 1.46 & 2.98 & 0.39 & $<0.001$ \\
\hline $\begin{array}{l}\text { Stereo-absent free space } \\
\text { binocular vs monocular }\end{array}$ & 0.62 & -0.45 & 1.70 & 0.55 & 0.260 \\
\hline $\begin{array}{l}\text { Stereo-normal free space } \\
\text { binocular vs stereo-absent free } \\
\text { space binocular }\end{array}$ & 3.03 & 1.84 & 4.22 & 0.61 & $<0.001$ \\
\hline $\begin{array}{l}\text { Stereo-normal free space } \\
\text { monocular vs stereo-absent } \\
\text { free space monocular }\end{array}$ & 1.43 & 0.24 & 2.62 & 0.61 & 0.018 \\
\hline $\begin{array}{l}\text { Stereo-normal monitor vs } \\
\text { stereo-absent monitor }\end{array}$ & 0.29 & -0.70 & 1.28 & 0.51 & 0.579 \\
\hline $\begin{array}{l}\text { Stereo-normal free space vs } \\
\text { monitor }\end{array}$ & 4.56 & 4.02 & 5.09 & 0.27 & $<0.001$ \\
\hline $\begin{array}{l}\text { Stereo-absent free space vs } \\
\text { monitor }\end{array}$ & 2.61 & 1.85 & 3.37 & 0.39 & $<0.001$ \\
\hline
\end{tabular}


Table 4 Stereo-absent group results

\begin{tabular}{|c|c|c|c|c|}
\hline \multirow{3}{*}{$\begin{array}{l}\text { Stereo-absent } \\
\text { participant }\end{array}$} & \multicolumn{4}{|c|}{ Number of balls in $50 \mathrm{~s}$ (mean of 3 attempts) } \\
\hline & \multicolumn{2}{|l|}{ Free space } & \multicolumn{2}{|l|}{ Monitor } \\
\hline & Both eyes & One eye & Both eyes & One eye \\
\hline 1 & 12.00 & 11.00 & 6.33 & 6.33 \\
\hline 2 & 12.33 & 13.00 & 5.67 & 8.33 \\
\hline 3 & 5.33 & 6.67 & 2.00 & 3.00 \\
\hline 4 & 10.67 & 9.67 & 7.67 & 7.67 \\
\hline 5 & 7.00 & 4.67 & 6.00 & 7.33 \\
\hline 6 & 9.33 & 9.33 & 7.33 & 7.00 \\
\hline 7 & 7.67 & 9.67 & 6.00 & 7.67 \\
\hline 8 & 10.00 & 6.00 & 5.00 & 4.00 \\
\hline 9 & 8.67 & 8.33 & 2.33 & 3.00 \\
\hline 10 & 10.67 & 10.00 & 6.00 & 8.00 \\
\hline 11 & 8.00 & 7.67 & 5.67 & 6.67 \\
\hline 12 & 8.33 & 7.00 & 6.33 & 5.67 \\
\hline 13 & 7.00 & 9.33 & 6.33 & 7.00 \\
\hline 14 & 10.33 & 7.33 & 9.00 & 6.33 \\
\hline 15 & 9.00 & 7.33 & 8.67 & 6.67 \\
\hline Mean & 9.09 & 8.47 & 6.02 & 6.31 \\
\hline SEM & 0.50 & 0.55 & 0.50 & 0.44 \\
\hline
\end{tabular}

\section{DISCUSSION}

Stereopsis is the perception of depth achieved by the analysis of the relative disparity of images elements projected onto the two retinae. ${ }^{1}{ }^{6}$ However, our visual perception of an object's distance also varies according to its size, shape and shading, which constitute monocular cues. Object interposition, relative distortion and the phenomenon of motion parallax also allows for appreciation of depth. ${ }^{78}$ In summary, although true stereopsis is only possible with binocular vision, indirect appreciation of a $3 \mathrm{D}$ world is feasible through innate interpretation of monocular and motor cues.

\section{Direct vision}

Our results show that, in free space and under direct vision, participants with normal stereoacuity performed significantly better when using both eyes compared with one eye (figure 4). This finding is not surprising and is well reported in the literature. Studies involving simple prehensile and buzz-wire tasks have shown a binocular advantage in almost every indicator of performance for stereo-normal participants, concluding that there

Free Space Viewing Condition

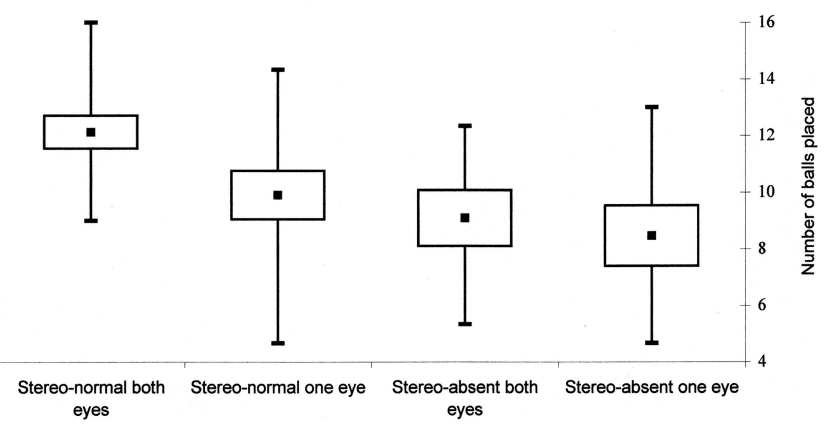

Figure 4 Task performance in free space (under direct vision). Median (squares), 1st-3rd quartile (boxes) and minimum/maximum (error bars).
Monitor Viewing Condition

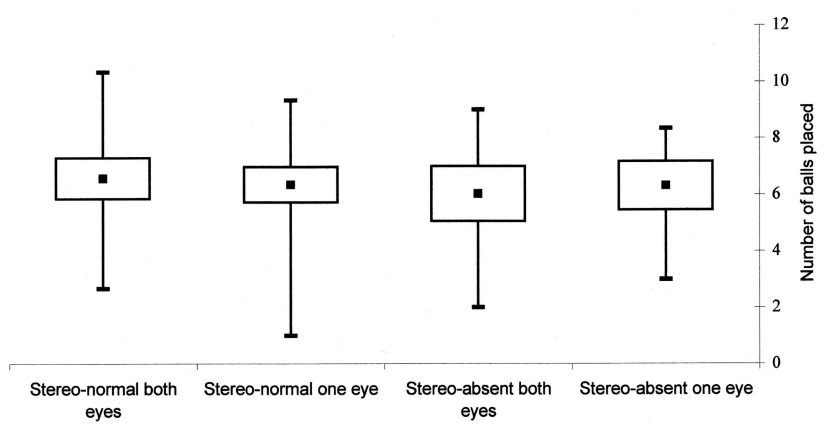

Figure 5 Task performance under monitor vision. Median (squares), 1st-3rd quartile (boxes) and minimum/maximum (error bars).

is a significant loss of visual information associated with monocular viewing. ${ }^{9} 10$

Within-group analysis of our data from participants with absent stereoacuity showed that they were not advantaged by having both eyes open when performing the task under direct vision (figure 4). Evidence from catching and grasping studies with one or both eyes open conditions suggest that stereodeficient participants perform similarly under either viewing condition, while stereo-normal participants catch significantly more balls with both eyes open. ${ }^{11} 12$

Between-group analysis of our data reveals a significant advantage to the stereo-normal group, in free space with both eyes open, when compared with the stereo-absent group (figure 4). These findings are also consistent with studies that looked at various fine motor, grasping and basic surgical skills tasks, to compare performance of patients with amblyopia, strabismus or weak stereoacuity to that of stereo-normals. ${ }^{13-16}$ Interestingly, there was evidence that the stereo-normal group free-space performance was also better than the stereo-absent group when one eye was occluded, although this trend was much less marked (table 3).

It is worth mentioning that these differences between the two groups could potentially be due to the issue of binocular rivalry. Since opaque occlusion was used, stereo-deficient participants may not have been affected the same way as the stereo group, since they have had long-term suppression. ${ }^{17}$

Various studies have considered the exact mechanisms of binocular advantage. Loftus et al suggest that the kinematic differences seen are a result of perceptual uncertainty. They conclude that, while binocularity does provide useful 'on-line' information during prehension, its removal will not necessarily affect performance in an environment where the brain is supplied with multiple other stimulus cues. ${ }^{18}$ Bradshaw et al tested this by comparing task performance under binocular, monocular and biocular (identical views to each eye to remove disparity) conditions. They found that monocular and biocular conditions yielded similar performances, and concluded that deficits in monocular performance can be attributed to lack of local depth information specified by binocular disparity. ${ }^{19}$ Our results concur with the latter, suggesting that binocular cues afforded by high-grade stereovision in the stereo-normal group convey a significant advantage to free-space task performance.

Traditionally, stereopsis has been considered essential to achieve surgical competence, with many training programmes, in particular, ophthalmology, requiring stereo testing at 
application. ${ }^{20}$ There is evidence emerging from microsurgical simulation studies that suggests stereopsis may not be essential to achieve surgical competency in $3 \mathrm{D}$ conditions. Although stereo-deficient participants perform worse on average than their stereo-normal counterparts, there are several isolated exceptions to this trend (table 4) and, thus, the predictive validity of stereopsis and microsurgical performance remains unclear. $^{21} 22$ In 2006, Binenbaum and Volpe performed a national survey to assess surgical competency of ophthalmology residents. They found that, of residents reported to have difficulty mastering surgical skills due to poor hand-eye coordination and intraoperative judgement, almost all overcame these problems (with further training as required) and most (92\%) became practising ophthalmologists, the majority of which $(65 \%)$ were surgeons. ${ }^{23}$

\section{Monitor}

We found that there is no statistically significant difference between stereo-normal and stereo-absent task performance using the monitor of a laparoscopy box trainer with either one or both eyes open (figure 5).

Modern surgery is becoming increasingly minimally invasive, and the operative field view is most frequently provided by a monitor that displays 2D images (as in laparoscopy), which may offer a more accessible route for stereo-deficient trainees pursuing a career in surgery. There is a paucity of evidence regarding the effects of absent stereopsis on surgical performance under 2D viewing conditions, and further study is needed to assess stereodeficient trainee proficiency in minimally invasive surgery and, in particular, their ability to convert to open surgery where necessary.

We postulated that those participants with long-term absence of stereoacuity may demonstrate adaptations to the lack of binocularity, such as the development of enhanced sensitivity to monocular and proprioceptive cues. Using the 'pea-on-a-peg' task, we attempted to minimise haptic feedback and highlight any visual adaptations. There is reported evidence of long-term adaptation to absence of stereoacuity in bead-threading tasks, ${ }^{16}$ however, it is worth noting that this task is much more reliant on proprioceptive feedback and, as such, may not represent enhanced interpretation of monocular visual cues. This idea is supported by Melmouth et al, ${ }^{12}$ who report that participants with long-term stereo-deficiency demonstrated different grip application than stereo-normals, suggestive of adaptations in tactile and kinaesthetic feedback mechanisms. Interestingly, it has been reported that surgeons appear to adapt to the non-stereo viewing conditions of laparoscopy, and that greater reliance on stereopsis was a negative factor in their surgical performance. ${ }^{24}$ However, our results did not suggest that the stereo-absent participants had developed an enhanced assimilation of monocular or motor visual cues, and it is possible that the apparent adaptations seen in surgeons are, in fact, a result of equipment familiarity and superior proprioceptive feedback.

In each viewing condition, average task performance under direct vision was better than the equivalent condition on the monitor. In the stereo-normal group, the estimated difference of means from free space to monitor was 4.56 (95\% CI 4.02 to $5.09)$, while that of the stereo-absent group was $2.61(95 \% \mathrm{CI}$ 1.85 to 3.37 ), in both cases $\mathrm{p}<0.001$ (table 3 ). This suggests that the monitor condition represents more than just a loss of binocular disparity. Gallagher et al, looked at three groups' performance of a simple cutting task either under binocular direct vision, monocular direct vision or via a monitor. They reported a binocular advantage, as expected, but also showed that monocular performance was significantly better than monitor performance, due to the poorer image quality provided by the monitor, thus diminishing the monocular cues. ${ }^{8}$ These results are in keeping with our data, and the significant deterioration in performance from direct vision to monitor conditions may result from relative degradation of image quality or simply be a consequence of the unfamiliar and restrictive environment afforded by the box trainer.

Despite attempts to prevent confounding, there are limitations to our study. With regards to testing ocular dominance, results can vary depending on the test. ${ }^{25}$ It should also be noted that three of the 15 stereo-absent participants (20\%) had an alternating manifest strabismus, and hand-eye coordination may have been affected if alternation occurred during task performance with both eyes open (table 1).

Additionally, some stereo-deficient participants were insightful of the fact that their hand-eye coordination might be reduced. The mere knowledge of having strabismus may have induced demand characteristics in this group.

Some studies have suggested that laparoscopy operative skill is related to age, gender, lateral dominance, video-game and musical instrument experience. ${ }^{26-28}$ While these may serve as confounding variables that influence subject performance, they were not factored in during our experimental design, and further study with careful quantification and control of variables is necessary.

In summary, we found that stereo-absent participants' performance on a $2 \mathrm{D}$ video-assisted surgical system is equivalent to that of their stereo-normal counterparts. As expected, we also found that stereo-absent participants perform significantly worse, on average, than stereo-normals in free space. However, we noted several cases where the degree of stereopsis did not correlate with task performance in free space with both eyes open. It is likely that surgical trainees with absent stereoacuity can achieve acceptable levels of surgical competence in minimally invasive surgery. Given the lack of a conclusive correlation between stereoacuity and surgical competence, we would not advocate the use of a stereopsis screening tool to predict technical aptitude in surgical trainees.

Acknowledgements Mr Bimbi Fernando and Mr Pasquale Berlingieri for their assistance with the simulation equipment and facilities. Dr John Hurst, Miss Anna Maino and the UCL Statistics Department for assistance in study design and data analysis.

Contributors Conception and design: SJ, NU, EB and LG. Data collection: EB, NU and LG. Analysis and interpretation: EB, NU and KR. Preparation: EB, NU, KR and SJ. Supervision: SJ.

\section{Competing interests None.}

Patient consent Obtained.

Ethics approval Camberwell St Giles National Research Ethics Service, London.

Provenance and peer review Not commissioned; externally peer reviewed.

Data sharing statement Please contact the corresponding author for further questions regarding data sharing.

Open Access This is an Open Access article distributed in accordance with the Creative Commons Attribution Non Commercial (CC BY-NC 3.0) license, which permits others to distribute, remix, adapt, build upon this work non-commercially, and license their derivative works on different terms, provided the original work is properly cited and the use is non-commercial. See: http://creativecommons.org/ licenses/by-nc/3.0/

\section{REFERENCES}

1 Wheatstone C. Contributions to the physiology of vision-Part the first. On some remarkable, and hitherto unobserved, phenomena of binocular vision. Phil Trans $R$ Soc Lond 1838;128:371-94.

2 Fielder AR, Moseley MJ. Does stereopsis matter in humans? Eye (Lond) $1996 ; 10: 233-8$ 
3 Ansons MA, Davis H. Diagnosis and management of ocular motility disorders, 3rd edn. Oxford: Blackwell Publishing, 2001.

4 Schreuder HWR, van den Berg CB, Hazebroek EJ, et al. Laparoscopic skills training using inexpensive box trainers: which exercises to choose when constructing a validated training course. BJOG 2011;118:1576-84.

5 Twisk JWR. Applied longitudinal data analysis for epidemiology: a practical guide. Cambridge: Cambridge University Press, 2003.

6 Barlow HB, Blakemore C, Pettigrew JD. The neural mechanism of binocular depth discrimination. J Physiol 1997;193:327-42.

7 Westheimer G. The Ferrier Lecture, 1992 —seeing depth with two eyes: stereopsis. Proc Biol Sci 1994;257:205-14.

8 Gallagher $A G$, Ritter EM, Lederman $A B$, et al. Video-assisted surgery represents more than a loss of three-dimensional vision. Am Jour Surg 2005;189:76-80.

9 Melmouth DR, Grant S. Advantages of binocular vision for the control of reaching and grasping. Exp Brain Res 2006;171:371-88.

10 Read JC, Begum SF, McDonald A, et al. The binocular advantage in visuomotor tasks involving tools. Iperception 2013;4:101-10.

11 Mazyn LIN, Lenoir M, Montagne $G$, et al. The contribution of stereo vision to one-handed catching. Exp Brain Res 2004;157:383-90.

12 Melmouth DR, Finlay AL, Morgan MJ, et al. Grasping deficits and adaptations in adults with stereo vision losses. Inv Ophthalmol Vis Sci 2009;50:3711-20.

13 Suttle CM, Melmouth DR, Finlay AL, et al. Eye-hand co-ordination skills in children with and without amblyopia. Invest Ophthalmol Vis Sci 2011;52:1851-64.

14 Barry GP, Simon JW, Auringer D, et al. Performance of strabismic participants using a validated surgical training module: a pilot study. J AAPOS 2009:13:350-3.

15 Suleman R, Yang T, Paige J, et al. Hand-eye dominance and depth perception effects in performance on a basic laparoscopic skills set. JSLS 2010;14:35-40.
16 O'Connor AR, Birch EE, Anderson S, et al. The functional significance of stereopsis. Invest Ophthalmol Vis Sci 2010;51:2019-23.

17 Smith EL III, Levi DM, Manny RE, et al. The relationship between binocular rivalry and strabismic suppression. Invest Ophthalmol Vis Sci 1985;26:80-7.

18 Loftus A, Servos P, Goodale MA, et al. When two eyes are better than one in prehension: monocular viewing and end-point variance. Exp Brain Res 2004;158:317-27.

19 Bradshaw MF, Elliott KM, Watt SJ, et al. Binocular cues and the control of prehension. Spat Vis 2004;17:95-110.

20 Royal College of Ophthalmologists Specialist Training Curriculum. http://curriculum. rcophth.ac.uk/ost (accessed 6 Sept 2013).

21 Sachdeva R, Traboulsi El. Performance of patients with deficient stereoacuity on the EYESi microsurgical simulator. Am J Ophthalmol 2011;151:427-33.

22 Waqar S, Williams 0 , Park J, et al. Can virtual reality simulation help to determine the importance of stereopsis in intraocular surgery? Br J Ophthalmol 2012;96:742-6.

23 Binenbaum G, Volpe NJ. Ophthalmology resident surgical competency: a national survey. Ophthalmology 2006;113:1237-44.

24 Shah J, Buckley D, Frisby J, et al. Depth cue reliance in surgeons and medical students. Surg Endosc 2003;17:1472-4.

25 Rice ML, Leske DA, Smestad CE, et al. Results of ocular dominance testing depend on assessment method. J AAPOS 2008;12:365-9.

26 Schueneman AL, Pickleman J, Freeark RJ. Age, gender, lateral dominance, and prediction of operative skill among general surgery residents. Surgery 1985;98:506-15.

27 Lynch J, Aughwane P, Hammond TM. Video games and surgical ability: a literature review. J Surg Educ 2010;67:184-9.

28 Boyd T, Jung I, Van Sickle K, et al. Music experience influences laparoscopic skills performance. JSLS 2008:12:292-4. 